\title{
The "Self-Disclosure" and "Self-Presentation" Views of Item Response Dynamics and Personality Scale Validity
}

\author{
John A. Johnson \\ Johns Hopkins University
}

\begin{abstract}
This study investigates whether objective self-report measures of personality are better regarded as sources of factual information about the self (i.e., as selfdisclosures) or as ways to instruct others about how one is to be regarded (i.e., as self-presentations). The two perspectives were compared by testing the unique, divergent predictions each perspective made about the kinds of personality variables associated with consistency in self-description. For three groups of subjects (155 normal adults, 69 murderers, and 47 college students) almost all of the "self-presentation variables" were correlated significantly with consistency, whereas none of the "self-disclosure variables" was correlated with the criterion. Limitations of the study are discussed.
\end{abstract}

When people talk about themselves-whether in a laboratory experiment, in psychotherapy, or in everyday life - their verbal reports can be conceptualized as either simple factual communications about the self (i.e., self-disclosure) or as ways to instruct others about how they are to be regarded (i.e., self-presentation): The distinction between self-disclosure and self-presentation has been a common topic of concern to social psychologists, personologists, and clinicians (Shaver, 1977, pp. 330-339; Snyder \& Swann, 1976; Wylie, 1974, pp. 63-86).

Responses to items on objective self-report measures of personality similarly can be regarded as self-disclosures or self-presentations. A self-disclosure view of item response dynamics would hold that endorsement of a personality item such as "I read 15 books a year" is simply a factual communication about the self (i.e., how many books one reads). From a self-presentational view, endorsement of that item is not merely a description of one's behavior but a social act intended to instruct others about how one

The author thanks Pam Horn for her assistance in scoring and coding the data and William S. Laufer for providing his CPI data on the group of murderers.

An earlier version of this article was presented at the 88 th annual convention of the American Psychological Association, Montreal, Canada, September 1980.

Requests for reprints should be sent to John A. Johnson, Department of Psychology, Johns Hopkins University, 34th and Charles Streets, Baltimore, Maryland 21218 is to be regarded - in this case, perhaps as an intellectual, scholarly individual. (See Jackson, 1980, for a review of these and other theories of item response dynamics.)

The present research examines the selfdisclosure and self-presentation perspectives and investigates which is more appropriate for understanding the dynamics underlying responses to personality scale items. The two views are not completely mutually exclusive, of course. Self-presentation may entail giving factual information about oneself; however, it may involve providing false information to project a desired public self-image. The self-disclosure perspective, on the other hand, conceptualizes item responses as veridical information about the self without regard for their potential for projecting public self-images. The self-presentation view therefore incorporates the self-disclosure perspective, but goes beyond it.

Despite some overlap, the two viewpoints are nonetheless unique enough to generate different propositions about the factors influencing the validity of personality scales. After explicating each item response theory, this article presents a study that tests each view's propositions about test validity.

\section{Test Validity}

Before examining the two item response theories' propositions about test validity, it might be useful to review several standard 
definitions of validity. "Test validity" has many different meanings (APA, 1974; Cronbach \& Meehl, 1955), but the notion can be reduced to one central meaning: A valid test faithfully measures or represents what it is intended to represent. A "loneliness scale" is valid if it measures loneliness, not anxiety. One can test the validity of such a scalethat is, how well scores on the scale represent actual loneliness-by observing whether scale scores covary in a meaningful way with other sources of information. Depending on the type of other information gathered, one can calculate different "types" of validity coefficients. Actually we do not have different types of validity (in all cases we want to know whether the scale measures loneliness) but, rather, different criteria for testing the validity of the scale.

First, one might want to see whether scores on the loneliness scale correlate with scores gathered with the same scale at a later time. Assuming that the trait of interestloneliness - is fairly stable, we would expect a high correlation if the test is valid. Commonly called a coefficient of reliability, a high test-retest correlation is usually considered a necessary but insufficient indicator of test validity.

Second, scores on the loneliness scale should have a meaningful pattern of correlations with other validated self-report questionnaires. We might expect moderate negative correlations with a measure of sociability, moderate positive correlations with measures of shyness and depression, and strong correlations with other measures of loneliness.

Third, scores on the loneliness scale should have a meaningful pattern of correlations with observers' ratings of sociability, shyness, depression, loneliness, etc. If the loneliness scale correlates in the right direction with information reported by observers as well as those taking the test, it lends a measure of objectivity to the test.

Finally, scores on the loneliness scale should have weak but consistent correlations with life events such as suicide. The expected correlations are small because life events are complex and overdetermined. After all, there are many reasons one might commit suicide besides being lonely.
Considered individually, a correlation between the loneliness scale and any single criterion indicates criterion-related validity (concurrent validity if there is no time lag between self-report and criterion but predictive validity if the self-report precedes the criterion). If scores on the scale are embedded in a meaningful network of relationships with other self-reports, observer ratings, and life events, or what Cattell (1973) calls Q-, $L(R)$-, and $L(O)$-data, the test is said to possess construct validity. The self-disclosure and self-presentational views on test validity are presented below.

\section{Self-Disclosure}

The self-disclosure view holds that item responses are best conceptualized as simple reports (hopefully veridical) about one's actual behavior or self-perceptions. The view is predicated on the assumption that, ideally, we should observe over a period of time the people we wish to test in order to sample their social behavior (cf. Tyler, 1963). Because such a task is inconvenient, we administer personality questionnaires, hoping the "testees" will honestly and accurately report their actual behaviors, moods, and attitudes. To depend on each testee's honesty and observational skills, however, is to encounter a number of special problems (e.g., faking good or bad, unique anchor points for self-ratings; the inability of people to report unconscious motives; acquiescence and extreme response sets). Because many psychologists subscribe to the self-disclosure view, the history of personality testing has been a series of efforts to overcome these impediments to valid assessment.

Several solutions to the problems mentioned above have been offered. One solution, eloquently defended by Meehl (1945), is simply not to worry about why persons answer personality items as they do, but rather to concentrate on the empirical correlates of these responses. Though logically defensible, this solution ignores the larger question: What are people actually doing when they respond to items?

Solutions to other, specific problems include selecting items with neutral social desirability, balancing items of equal social 
desirability in a forced-choice format, and using only items that refer to concrete, specific behavior or biographical facts. Finally, Rorer (1965) and Block (1965) present substantial evidence showing that response sets and styles do not play an important role in personality testing.

The portion of the self-disclosure theory of item response that explains test validitythat is, why personality scales predict other behavior, performances, and activities-is mostly implicit and unspecified, but seems to take one of two forms. Personality scales predict other phenomena because either (a) highly frequent behavior (as reported on the scale) is bound to recur or (b) the scale measures some underlying trait that has directed past behavior and will direct future behavior. In both cases, an item response is seen as reflecting veridical, factual information about the self (either behavioral traits or underlying, dynamic traits) that can be used to predict other information.

This explanation for validity implies that any conditions that would encourage the subject to lie or in some way misrepresent himself or herself would detract from test validity. Consequently the most valid test scores should come from people who are honest, responsible, and well socialized. Valid scores should also come from people who are self-controlled; conversely, people who are impulsive and changeable should give scores with lower validity.

\section{Self-Presentation}

The self-presentation view of item response dynamics hypothesizes that an item response is best conceptualized not as a description of "how one really is" but, rather, as a picture of how one generally would like to be regarded. The main impetus for this view comes from the writings of Goffman (1959), Mead (1934), and Sarbin (1954); Gough (1948) was one of the first personologists to take a self-presentational view of the personality assessment process.

An example of the self-presentation view is provided by the research on social desirability. The social desirability view claims that people will answer personality items so as to be regarded in a favorable light, re- gardless of the item content and the truthfulness of their responses. Subsequent research has demonstrated that the strong version of this claim, if not simply false, is at least too simplistic. People do respond to item content, not just the social desirability of the item (Block, 1965).

A more developed self-presentational view (e.g., Johnson \& Hogan, in press; Mills \& Hogan, 1978; Taylor, Carithers, \& Coyne, 1976) hypothesizes that people have an image of themselves that they would like others to credit them with (e.g., as a conscientious, conservative banker or as a creative, uninhibited artist) and that they evaluate the content of personality items, endorsing those that convey aspects of their self-image.

As was the case with the self-disclosure viewpoint, the self-presentation-position explanation of why personality scales predict other behaviors is not precisely developed. At first it would appear that test scores that reflect the way people would like to be regarded have little relation to the way they are regarded. The theory assumes, however, that people's strategies for self-presentation are fairly consistent over time, and since test taking is a form of self-presentational behavior similar to what goes on in everyday social interaction, test scores covary with other social behaviors. ${ }^{1}$

From the self-presentation point of view, literal truth or falsity of item responses has little consequence for test validity; what is important is that the test taker has some (at least intuitive) awareness of the social significance of the statements he or she is endorsing (i.e., the social identity one is

\footnotetext{
${ }^{1}$ Mills and Hogan (1978) regard the self-presentation process as primarily automatic, reflexive, and unconscious; the habitual nature (in the Jamesian sense) of self-presentation accounts for consistency in behavior. Self-conscious self-presentations are seen as infrequent events that occur only under very specific circumstances. Furthermore, Hogan (Note 1) points out that self-conscious performances are awkward, stilted, exaggerated, unnatural, affected, and unconvincing. Snyder (1974), on the other hand, regards self-consciousness as a characteristic of the most skilled social role players and maintains that the greater the degree of self-monitoring and social adroitness, the less valid the resultant test scores (see Snyder \& Swann, 1976). In my opinion, further conceptual and empirical research is needed to clarify the relationships among self-consciousness, social skills, and test validity.
} 
painting through the test medium). Consequently, clarity of self-image and social roleplaying and role-taking skills are expected to increase the validity of self-reports.

\section{Testing the Competing Viewpoints}

From the above, we can see that the selfdisclosure and self-presentation views of item response dynamics make unique, divergent predictions about which variables will affect the validity of self-reports. The self-disclosure view holds that honesty, cooperativeness, and self-control will moderate test validity; the self-presentation view holds that variables such as clarity of self-image and social acuity will moderate test validity. The present study tests the adequacy of the competing viewpoints by examining how well each group of proposed moderator variables predicts the consistency of self-description, where consistency is operationalized as responding in an identical fashion to items that appear twice on a personality scale. In terms of the types of validity discussed above, consistency is a form of concurrent validity and is similar to a split-half reliability coefficient.

Response consistency was chosen as a criterion because the self-disclosure and selfpresentation views make clear but divergent predictions about the personality variables associated with response consistency. Consider how each perspective would explain why a person might respond yes to an item the first time it is encountered and no the second time. According to the self-disclosure view, item responses represent actual behavior or self-perceptions; inconsistency from this perspective could be interpreted as (a) misrepresentation from an uncooperative troublemaker or (b) accurate accounts from someone whose behaviors and self-perceptions are continuously changing. Inconsistency should covary with traits like impulsivity, dishonesty, and behavioral lability; the most valid (consistent) test scores should come from people who are honest, responsible, and well socialized, because they will describe themselves in a conscientious and factual manner.

A self-presentational perspective, on the other hand, suggests that self-report inconsistency is a function of an ill-defined social identity or lack of skills in social communication and interaction. Someone who is inconsistent might have little practice at or interest in social interaction (have introverted as opposed to extraverted tendencies), might have a vague or complex self-concept that is not easily communicated through the test medium, or might be unable to perceive test items as vehicles from which an unspecified audience (generalized other; cf. Mead, 1934) will make inferences about his or her identity or self-concept. The most valid test scores should come from people who are sociable, socially aware, and selfassured and who are able to take the perspective of others.

The present study operationalizes test validity as consistency in self-description and operationalizes the two sets of moderator variables proposed by each item response theory with several well-validated personality scales, described in the Method section. Positive correlations between consistency and the proposed moderator variables support the respective theories; lack of correlations undermine them.

\section{Method}

\section{Subjects}

The study used protocols from three separate groups. The first group consisted of 155 normal adults ( 131 men, 24 women). The second group contained 69 murderers (all men) serving life sentences at the Maryland State Penitentiary. The third group consisted of 22 male and 25 female undergraduate students from Johns Hopkins University. All subjects had completed the personality scales described here as a part of previous investigations. The present study reanalyzed the data that were on file.

\section{Personality Measures}

The first two groups had completed the California Psychological Inventory (CPI; Gough, 1975). In addition, the first group took a version of Sarbin and Hardyck's (1955) Stick Figure Test (SFT). The third group had completed the Philosophies of Human Nature Scale (PHN Scale; Wrightsman, 1974) and the Adjective Check List (ACL; Gough \& Heilbrun, 1965).

Criteria. The criterion of response consistency for the first two groups was the number of times a consistent response was given to the 12 items that appear twice on the CPI. That is, a "consistency point" was given each 
time a person answered true or false on both encounters with the same item. Scores could range from 0 to 12 on this "consistency scale."

To ensure that any results obtained from the first two groups were not artifacts of the instrumentation, a different measure of response consistency was used for the third group - consistent responses to items on the PHN Scale. This 84 -item scale is not as long as the 480 -item CPI, and it does not contain duplicate items. It does, however, contain item pairs that are nearly semantic paraphrases or opposites. An example of a paraphrase pair is "Some people are too complicated for me to figure out" and "People are so complex, it is hard to know what "makes them tick." An opposite pair is "I find that my first impression of a person is usually correct" and "I find that my first impressions of people are frequently wrong." Six such paraphrases and 10 such opposites were chosen to define a consistency scale. Here, consistency was computed as the number of responses made in the same direction to a paraphrase and in opposite directions for an opposite pair. Scores could vary between 0 and 16 on this scale.

Self-disclosure predictor variables. From the selfdisclosure perspective, inconsistency is a function of impulsivity, dishonesty, and/or behavioral lability. In the first two groups, these tendencies were assessed with the Responsibility, Socialization, Self-Control, and Flexibility scales of the CPI. The ACL scales that correlate most highly with these CPI scales-Self-Control, Lability, Order, and Change-were used as self-disclosure predictor variables in the third group.

Self-presentation predictor variables. The self-presentation view holds that three major types of personality variables should covary with item response consistency: extraversion, what has been called perceptual conformance (see Sarbin \& Hardyck, 1955), and social skills. Extraverts should be more consistent than introverts because (a) they have relatively simpler and more clearly defined self-concepts that are easier to communicate and (b) they have more interest and practice than introverts in social communication (cf. Jung, 1923). Extraversion was assessed in the first two groups with the Dominance, Sociability, Social Presence, and Self-Acceptance scales of the CPI. For the third group, the ACL scales that correlate highest with these CPI scales were used: Dominance, Self-Confidence, Achievement, and Exhibition.

Perceptual conformance is defined by Sarbin and Hardyck as the tendency to perceive social situations as one's peers do. Persons who interpret social situations (and personality items) idiosyncratically, rather than as their peers do, would tend to be unpredictable and inconsistent in their responses. Perceptual conformance was measured in the first group with the Stick Figures Test and in the first two groups with the CPI Communality scale. Gough (1968) says that those who score high on Communality will "be in tune with their peers and surroundings, will perceive as their peers perceive, and will form impressions that are sound, stable, and sensible" (p. 15).

Finally, role-taking and role-playing skills are important from the self-presentation view. These skills are assessed in the first two groups with Hogan's (1969)
Empathy scale, scorable from the CPI. Empathy-"the disposition or ability to anticipate or construe the feelings, expectations, and informational requirements of others" (Grief \& Hogan, 1973, p. 280)--is a social skill related to perceptual conformance and hence is predicted by self-presentation theory to be related to item response consistency.

\section{Results}

Means, standard deviations, and skewness of consistency scores were calculated for the three samples. For the 155 normal adults, $M=10.66, S D=1.39$; for the 69 murderers, $M=9.25, S D=2.55$; and for the 47 students, $M=11.12, S D=2.24$. All three distributions were markedly skewed toward the high end of the scale. This is not surprising, given the previous study by Goldberg and Rorer (1964) that showed between $76 \%$ and $97 \%$ consistent responses to items appearing twice on the CPI. This skewness, along with the fact that the consistency scale for the third group was different from the one used for the first two groups, makes statistical comparisons between groups inappropriate, unless one were to use elaborate transformations.

Pearson correlation coefficients between the consistency scores and the moderator variables proposed by the two item response theories were computed. Because the consistency scores are skewed, two nonparametric correlation coefficients (Spearman's rho and Kendall's tau) also were calculated. The results for the nonparametric correlations were nearly identical to those using the Pearson correlations; hence only the Pearson $r s$ are reported here.

The pattern of correlation coefficients, shown in Table 1, clearly demonstrates that the "self-presentation variables" account for more variance in response consistency than do the "self-disclosure variables." Of the 17 correlations between the self-presentation variables and consistency, all are in the predicted direction, and 15 of the 17 are statistically significant. In contrast, of the 12 correlations between self-disclosure variables and consistency, five are in the wrong direction and none reached statistical significance.

As a final test, composite self-disclosure and self-presentation scores were created for 
Table 1

Personality Correlates of Item Response Consistency

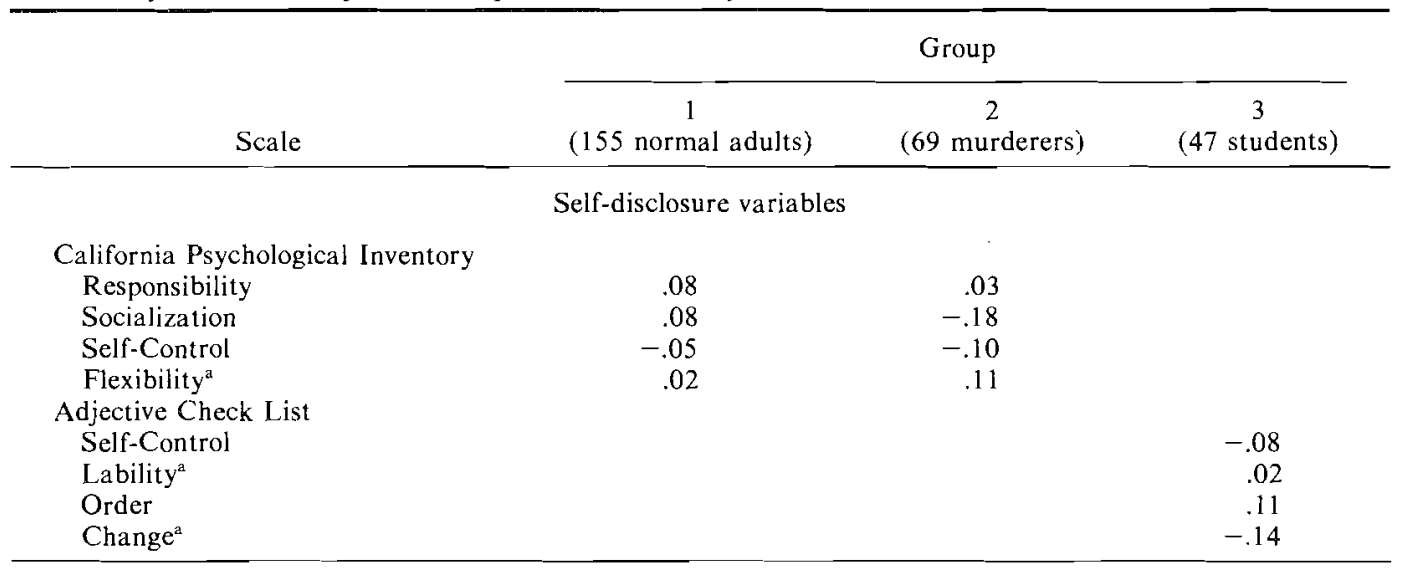

Self-presentation variables

Stick Figure Test
California Psychological Inventory
Dominance
Sociability
Social Presence
Self-Acceptance
Communality
Empathy
Adjective Check List
Self-Confidence
Dominance
Achievement
Exhibition

$\begin{array}{ll}.22^{* * *} & \\ .21^{* * *} & .20^{* *} \\ .12^{*} & .27^{* * *} \\ .07 & .39^{* * *} \\ .21^{* * *} & .38^{* * *} \\ .28^{* * *} & .75^{* * *} \\ .20^{* *} & .14^{*}\end{array}$

Note. Consistency for Groups 1 and 2 was measured with the California Psychological Inventory; for Group 3 with the Philosophies of Human Nature Scale.

Direction of scoring reversed.

${ }^{*} p<.10{ }^{* *} p<.05{ }^{* * *} p<.01$. (All one-tailed tests.)

the subjects in Group 1 by summing the individual CPI scores. Median splits were made with the two composites, forming four subgroups: (a) low on both the self-disclosure and self-presentation composites $(n=45)$, (b) low on the self-disclosure but high on the self-presentation composite $(n=35)$, (c) high on the self-disclosure but low on the self-presentation composite $(n=33)$, and (d) high on both composites $(n=42)$. A $2 \times 2$ analysis of variance on consistency scores for these four subgroups showed a main effect for the self-presentation composite, $F(1,151)=4.43, p<.05$; no effect for the self-disclosure composite, $F(1,151)=.002, n s$; and no interaction effect, $F(1,151)=.44$, ns. This analysis sup- ports the findings of the first analysis - that is, that self-descriptive consistency is related to extraversion, perceptual conformance, and social acuity but not to socialization, responsibility, and self-control.

\section{Discussion}

Considerable research over the past decade has sought to determine whether and to what degree human behavior is consistent and personality scales can predict nontest behavior. Although some progress toward resolving these issues has been made, most contributions have been limited to empirical demonstrations of consistency (e.g., Block, 1971 ) or to evaluations of the psychometric 
prerequisites for finding consistency (e.g., Epstein, 1979). These demonstrations are analogous to those provided by early astronomers who showed that the heavenly bodies move in regular, predictable ways. The position of this article is that just as progress in astronomy required a theory to account for regularities in planetary movements, progress in personality assessment requires a theory to account for consistency in test taking and social behavior. Rather than take one of two extremes - that people are totally consistent or inconsistent-the present study explores sources of systematic consistency and inconsistency, as predicted by the selfdisclosure and self-presentation views of item response.

The results of the present study show that certain personality variables do systematically moderate one type of behavioral consistencyconsistency of self-description. (Clearly, other types of behavioral consistency should be studied.) This is useful information for those who are developing or revising personality scales. The results imply that the best strategy for designing a valid scale is not to make lying or misrepresentation difficult, but to make selfpresentation as easy as possible to accommodate people with identity problems or modest social skills. It also suggests that social perceptiveness scales could be just as useful as "lie scales" for interpreting the validity of test scores.

Although the results of the present study overwhelmingly support a self-presentation conceptualization of test taking as contrasted with a self-disclosure view, the magnitude of the correlations is low (median $r=.21$ ). This suggests that there are other moderator variables and factors to consider in dealings with item response consistency. I will mention three and then point out the limitations of this study that can be corrected by future research.

First, properties of the test items need to be considered. Goldberg (1963) and Goldberg and Slovic (1967) have already discussed how item ambiguity and endorsement frequency affect the validity of personality scales. Other aspects of item content (e.g., whether the referent is to mood, self-perception, or behavior) may also moderate validity coefficients. There are also a myriad of grammatical and syntactic structures that could be studied (first vs. third person, active vs. passive voice, etc.)

Second, the present study is limited to selfreport measures of personality. Although the scales used in the study have been shown to be valid by previous research, the present study suggests that scores on these scales are not equally valid for everyone; that is, the scores are more valid for subjects high on extraversion, perceptual conformance, and empathy. Yet, in order to carry out the present study, it had to be assumed that the selfreport measures of honesty, self-control, extraversion, empathy, and other moderator variables had acceptable validity for all individuals. Future research can avoid this dilemma by using observer ratings of the personality moderator variables. Also, as mentioned above, types of consistency with more ecological significance than self-report/self-report consistency should be studied, such as self-report/peer description, peer/peer description, and self-ratings with life events.

Third, the study fails to deal with test conditions or instructional set. It is possible that certain test conditions (e.g., anonymity or mutual self-disclosure; cf. Jourard, 1964) make it more likely that self-disclosure of factual information will occur. Test administrators also have recourse to a number of "tricks" for obtaining information that do not require total cooperation from the subject (e.g., projective tests, cameras for monitoring nonverbal behavior, lie detectors, and fake lie detectors like the "bogus pipeline" cf. Jones \& Sigall, 1971; see also Scheibe, 1978, 1979). Other conditions (e.g., competing for a job) could encourage misrepresentation. In the only other study similar to this one, responsibility and socializationboth self-disclosure variables-were found to moderate consistency in self-description (Kilkowski, in press). If obtaining factual information is the goal of the tester, the tester should treat the testing situation as a form of social interaction by paying attention to social dynamics, that is, the goals of the test taker and the social expectations generated by the testing situation. 
A final comment concerns the need for a stronger conceptual foundation for personality assessment. I pointed out earlier that the self-disclosure and self-presentation accounts of why people exhibit consistencies and why scale scores predict behavior are, for the most part, implicit and unspecified. The trait version of self-disclosure theory postulates some sort of psychic entity that imparts regularity to behavior, whereas selfpresentation theory attributes consistency to stable self-images. Clearly, whether one appeals to traits, self-images, or any other personality concept, these terms need to be analyzed beyond their commonsense meanings. Furthermore, any theory of personality dynamics will remain incomplete until it explains how consistency is generated by personality characteristics. This task will not be easy, and it may involve philosophical issues (e.g., consistency as causal necessity vs. consistency as intentional, intelligent action; cf. Johnson, Note 2). Nonetheless, these questions must be asked and these issues addressed if we are to progress from a technology to a science of personality assessment.

\section{Reference Notes}

1. Hogan, R. Role theory as a depth psychology. Paper presented at the 87 th annual convention of the American Psychological Association, New York, September 1979.

2. Johnson, J. A. A theory of action to account for personality consistency. Unpublished manuscript, Johns Hopkins University, 1980.

\section{References}

American Psychological Association. Standards for educational and psychological tests (Rev. ed.). Washington, D. C.: Author, 1974.

Block, J. The challenge of response sets. New York: Appleton-Century-Crofts, 1965.

Block, J. Lives through time. Berkeley, Calif.: Bancroft Books, 1971.

Cattell, R. B. Personality and mood by questionnaire. San Francisco: Jossey-Bass, 1973.

Cronbach, L. J., \& Meehl, P. E. Construct validity in psychological tests. Psychological Bulletin, 1955, 52, 281-302.

Epstein, S. The stability of behavior: I. On predicting most of the people much of the time. Journal of Personality and Social Psychology, 1979, 37. 10971126 .
Goffman, E. The presentation of self in everyday life. Garden City, N.Y.: Anchor Books, 1959.

Goldberg, L. R. A model of item ambiguity in personality measurement. Educational and Psychological Measurement, 1963, 23, 467-492.

Goldberg, L. R., \& Rorer, L. G. Test-retest item statistics for the California Psychological Inventory. Oregon Research Institute Monograph, 1964, I, No. 4.

Goldberg, L. R., \& Slovic, P. Importance of test item content: An analysis of a corollary of the deviation hypothesis. Journal of Counseling Psychology, 1967, 14, 462-472.

Gough, H. G. The frame of reference of the Thematic Apperception Test. Journal of Clinical Psychology, 1948, 4, 90-92.

Gough, H. G. An interpreter's syllabus for the California Psychological Inventory. Palo Aito, Calif.: Consulting Psychologists Press, 1968.

Gough, H. G. Manual for the California Psychological Inventory (Rev. ed.). Palo Alto, Calif:: Consulting Psychologists Press, 1975.

Gough, H. G., \& Heilbrun, A. B., Jr. The Adjective Check List manual. Palo Alto, Calif.: Consulting Psychologists Press, 1965.

Grief, E., \& Hogan, R. Theory and measurement of empathy. Journal of Counseling Psychology, 1973, 20. $280-284$.

Hogan, R. Development of an empathy scale. Journal of Consulting and Clinical Psychology, 1969, 33, 307-316.

Jackson, D. N. Personality structure and assessment. In M. R. Rosenzweig \& L. W. Porter (Eds.), Annual Review of Psychology (Vol. 31). Palo Alto, Calif.: Annual Reviews, 1980.

Johnson, J. A., \& Hogan, R. Moral judgments and selfpresentations. Journal of Research in Personality, in press.

Jones, E. E., \& Sigall, H. The bogus pipeline: A new paradigm for measuring affect and attitude. Psychological Bulletin, 1971, 76, 349-364.

Jourard, S. M. The transparent self: Self-disclosure and well-being. Princeton, N.J.: Van Nostrand, 1964.

Jung, C. G. Psychological types (H. G. Baynes, Trans.). London: Kegan Paul, 1923.

Kilkowski, J. M. An empirical investigation of the consistency of self-ratings. Journal of Personality and Social Psychology, in press.

Mead, G. H. Mind, self, and society. Chicago: University of Chicago Press, 1934.

Meehl, P. E. The dynamics of "structured" personality tests. Journal of Clinical Psychology, 1945, 1, 297303.

Mills, C., \& Hogan, R. A role theoretical interpretation of personality scale item responses. Journal of Personality, 1978, 46, 778-785.

Rorer, L. The great response-style myth. Psychological Bulletin, 1965, 63, 129-156.

Sarbin, T. R. Role theory. In G. Lindzey (Ed.), Handbook of social psychology. Cambridge, Mass.: Addison-Wesley, 1954.

Sarbin, T. R., \& Hardyck, C. D. Conformance in role 
perception as a personality variable. Journal of Consulting Psychology, 1955, 19, 109-111.

Scheibe, K. E. The psychologist's advantage and its nullification: Limits of human predictability. American Psychologist, 1978, 33, 869-881.

Scheibe, K. E. Mirrors, masks, lies, and secrets. New York: Praeger, 1979.

Shaver, K. G. Principles of social psychology. Cambridge, Mass.: Winthrop, 1977.

Snyder, M. The self-monitoring of expressive behavior. Journal of Personality and Social Psychology, 1974, 30, 526-537.

Snyder, M., \& Swann, W. B. When actions reflect attitudes: The politics of impression mangagement.
Journal of Personality and Social Psychology, 1976. 34, 1034-1042.

Taylor, J. B., Carithers, M., \& Coyne, L. MMPI performance, response set, and the "self-concept hypothesis." Journal of Consulting and Clinical Psychology, $1976,44,351-362$.

Tyler, L. E. Tests and measurement. Englewood Cliffs, N.J.: Prentice-Hall, 1963.

Wrightsman, L. S. Assumptions about human nature: A social-psychological approach. Monterey, Calif.: Brooks/Cole, 1974.

Wylie, R. C. The self concept. Lincoln: University of Nebraska Press, 1974.

Received February 7, 1980 